\title{
Anchorage mechanisms of novel geometrical hooked-end steel fibres
}

\author{
Sadoon Abdallah • Mizi Fan
}

Received: 27 May 2016/Accepted: 20 December 2016/Published online: 20 February 2017

(C) The Author(s) 2017. This article is published with open access at Springerlink.com

\begin{abstract}
This study is aimed at fully understanding the anchorage mechanisms of steel fibres with novel hook geometries, e.g. 4DH and 5DH fibres, which were subjected to pull-out loading. The fibres were also embedded in four different matrixes with a compressive strength ranging from 33 to $148 \mathrm{MPa}$. The results showed that the anchorage and pull out behaviour was not only dependent on the geometry of the hooked end of steel fibres, but also closely related to the characteristics of matrix. Both maximum pullout load and total pull-out work of 5DH fibre were considerably higher than those of $4 \mathrm{DH}$ and the controlled $3 \mathrm{DH}$ fibres for all matrixes. All fibres embedded in normal strength concrete and medium strength concrete matrixes were completely pulled out without the occurrence of full deformation and straightening of the hook, while the controlled $3 \mathrm{DH}$ and 4DH fibres ruptured at hook portion when embedded in ultra-high performance mortar matrix. To fully utilize the high mechanical anchorage, 5DH fibres should be used for reinforcing high or ultra-high performance matrixes in practice.
\end{abstract}

\footnotetext{
S. Abdallah

College of Engineering, Design and Physical Sciences,

Brunel University, London, UK

M. Fan $(\bowtie)$

Brunel University London, Uxbridge, London UB8 3PH,

UK

e-mail: mizi.fan@brunel.ac.uk
}

Keywords Anchorage mechanism - Pull-out behaviour - Hook geometry - Matrix compressive strength $\cdot$ Fibre rupture and fibre efficiency

\section{Introduction}

Nowadays one of the main challenging topics of concrete industry is how to improve the tensile response of cementitious materials in terms of strength and ductility. It is well established that the addition of short fibres into concrete or mortar significantly enhances their strength in tension as well as controls the cracking propagation [1-4]. The fibre contribution is mainly reflected when the concrete cracking initiates and often enhances the post-cracking behaviour due to the improved stress transfer provided by the fibre bridging of the cracked sections $[5,6]$. In postcracking stage, the efficiency of fibres in transferring applied stresses is greatly dependent on interfacial bond properties between fibre and matrix [7]. Bond is the mechanism through which tensile forces are transmitted between the steel fibres and the surrounding cement paste [8]. A part of these forces are resisted by the cementitious matrix, whilst the remainder is resisted by the fibres [9]. The tensile strength of steel fibre-reinforced cementitious composites (SFRCCs) can be quite variable, depending mainly on the fibrematrix bond strength $[10,11]$. In case where the fibres have a weak bond with the matrix, the pull-out at low 
loads is likely to occur and thus does not contribute much to resisting the propagation of cracks [12]. Otherwise, if the bond is too strong, the fibre rupture may happen before they can fully contribute to the post-crack strength [13]. Therefore, the investigation of the bond mechanisms is a key factor to understand the tensile behaviour of SFRCCs $[14,15]$.

Among the various attempts which have been performed to enhance the bond-slip properties of SFRCCs, the most effective is mechanical anchorage [16]. Steel fibres for the use in cementitious materials are available in a number of length, diameter, and shape and metal types [15]. There are various forms of mechanical anchorage, such as hooks, buttons and paddles formed at the end of the fibre or along fibre length such as polygonal twisted, crimped and indented to introduce a mechanical contribution to overall pull-out behaviour [17]. Nevertheless, hooked end fibres are more widely used in cementitious composites compared with other types of steel fibres [16]. These fibres have a distinct advantage which slowly deforms during the pull-out process to generate high mechanical anchorage in the matrix [18]. The latter mechanism is based on the principle of plastic deformation of the end hook which results in an immense energy consumption to straighten the hook. Moreover, the mechanical interlock provided by fibre hook not only increases resistance to pull-out but also has significant effect on the whole tensile behaviour of SFRCCs [19]. To investigate the influence of fibre geometry on pull-out behaviour of SFRCCs, extensive pull-out tests have been done during the last three decades [20-22]. However, all single fibre pull-out tests have been conducted on hooked end fibres with two curvatures or hinges. Recently, the hooked-end steel fibres of improved shape were introduced, such 4D and 5D hooked-end ones. These fibres were designed to achieve high levels of fibre anchoring, tensile strength and ductility which provides for maximum performance. Therefore, mechanisms associated with pull-out behaviour of these new hooked end fibres (i.e. 4D and 5D) are not yet understood.

This paper experimentally investigates the pull-out behaviour of various hooked end fibres, dealing with varying parameters such as the geometry of end hooks, matrix compressive strength and fibre tensile strength, and quantify the effect of the hook geometry of 3DH, $4 \mathrm{DH}$ and $5 \mathrm{DH}$ fibres on pull-out response. The influence of matrix compressive strength on bond-slip characteristics was also discussed. The findings of this experimental investigation provide a better understanding of the bond mechanisms and efficiency of hooked end steel fibres with variation of matrix strength. This provides some fundamental information for efficient exploitation and application of these fibres which are recently introduced to the market. In addition, this investigation will also contribute to increase the database and in-depth knowledge on bond mechanisms of especially 4DH and 5DH steel fibres, which shall be most useful for future review of relevant codes and standards.

\section{Experimental program}

\subsection{Materials}

\subsubsection{Matrix}

Four different mixtures of normal strength concrete (NSC), medium strength concrete (MSC), high strength concrete (HSC) and ultra-high performance mortar (UHPM) were used. For the NSC, MSC and HSC matrix, the following components were used: Portland cement CEM II 32,5R and CEM III $52.5 \mathrm{~N}$, fly ash EN-450, sand (0-5 mm), combination of two particle sizes of crushed granite aggregates (C.G.A), $60 \% 6 \mathrm{~mm}$ and $40 \% 10 \mathrm{~mm}$, superplasticizer TamCem (23SSR) and water, for UHPM the component materials include Portland cement CEM III $52.5 \mathrm{~N}$, silica fume, ground quartz, fine sand (150-600) micrometres $(\mu \mathrm{m})$, superplasticizer, accelerator and water. The materials and mix proportion adopted in this study are summarized in Table 1 .

\subsubsection{Steel fibres}

Three types of commercially available Dramix hooked end steel fibres $(3 \mathrm{DH}, 4 \mathrm{DH}$ and $5 \mathrm{DH})$ with same length $(60 \mathrm{~mm})$, diameter $(0.90 \mathrm{~mm})$ and aspect ratio $(l / d=65)$ but different in the tensile strength and end hook geometry were used throughout. For each type of fibres, the end hook geometry of the fibres was electronically scanned and measured by using computer software (SUPRA $35 \mathrm{VP}$ ). The geometrical properties of each fibre type are depicted in Fig. 1 and detailed in Table 2. All other properties such as length $\left(L_{\mathrm{f}}\right)$ and, diameter $\left(d_{\mathrm{f}}\right)$ and yield strength $\left(f_{\mathrm{y}}\right)$ as 
Table 1 Mix design of mixtures $\left(\mathrm{kg} / \mathrm{m}^{3}\right)$ and cube compressive strength (28 days)

\begin{tabular}{|c|c|c|c|c|c|c|c|c|c|c|c|}
\hline \multirow{3}{*}{$\begin{array}{l}\text { Matrix } \\
\text { type }\end{array}$} & \multirow[t]{3}{*}{ Cement } & \multirow{3}{*}{$\begin{array}{l}\text { Silica } \\
\text { fume }\end{array}$} & \multirow{3}{*}{$\begin{array}{l}\text { Fly } \\
\text { ash }\end{array}$} & \multirow[t]{3}{*}{ Quartz } & \multicolumn{3}{|c|}{ Aggregate } & \multirow{3}{*}{$\begin{array}{l}\text { Superplas- } \\
\text { ticizer }\end{array}$} & \multirow[t]{3}{*}{ Water } & \multirow[t]{3}{*}{$W / B$} & \multirow[t]{3}{*}{$f_{\mathrm{c}}(\mathrm{MPa})$} \\
\hline & & & & & \multirow{2}{*}{$\begin{array}{l}\text { C.G.A } \\
6-8 \mathrm{~mm}\end{array}$} & \multicolumn{2}{|l|}{ Sand } & & & & \\
\hline & & & & & & $0-4 \mathrm{~mm}$ & $150-600 \mu \mathrm{m}$ & & & & \\
\hline NSC & $364^{\mathrm{a}}$ & - & - & - & 979 & 812 & - & - & 200 & 0.55 & 33 \\
\hline MSC & $350^{\mathrm{b}}$ & - & 107 & - & 660 & 1073 & - & - & 205 & 0.45 & 52 \\
\hline HSC & $480^{\mathrm{b}}$ & - & 45 & - & 850 & 886 & - & 6 & 210 & 0.40 & 71 \\
\hline UHPM & $710^{\mathrm{b}}$ & 230 & - & 210 & - & - & 1020 & 30.7 & 127 & 0.11 & 148 \\
\hline
\end{tabular}

${ }^{\text {a }}$ Portland-limestone cement CEM II 32,5R

b Portland cement CEM III $52.5 \mathrm{~N}^{\prime}$

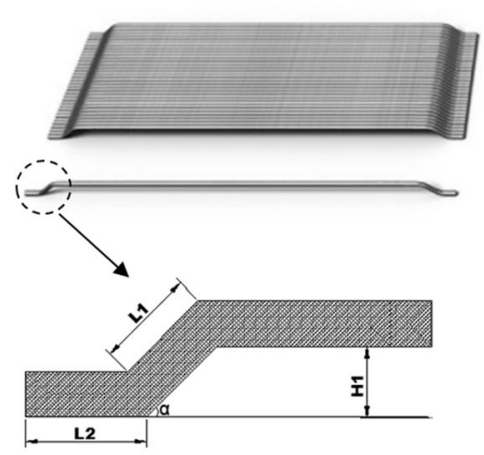

\section{$3 \mathrm{D} 65 / 60 \mathrm{BG}$}

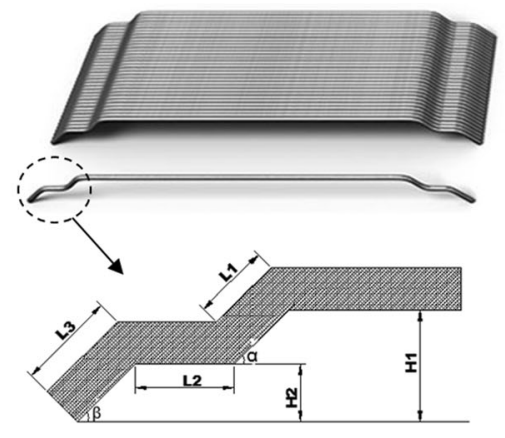

$4 \mathrm{D} 65 / 60 \mathrm{BG}$

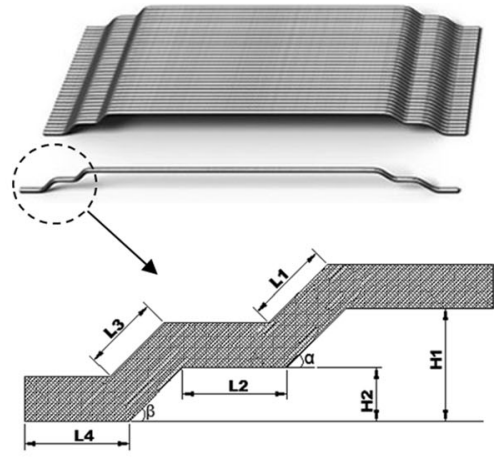

5D $65 / 60 \mathrm{BG}$

Fig. 1 Geometrical properties of hooked end steel fibres

Table 2 The measured geometric properties of fibre hook

\begin{tabular}{|c|c|c|c|c|c|c|c|c|c|c|c|}
\hline \multirow[t]{2}{*}{ Fibre type } & \multirow[t]{2}{*}{$f_{\mathrm{y}}(\mathrm{MPa})$} & \multirow[t]{2}{*}{$l_{\mathrm{f}}(\mathrm{mm})$} & \multirow[t]{2}{*}{$d_{\mathrm{f}}(\mathrm{mm})$} & \multicolumn{4}{|c|}{ Hook length (mm) } & \multicolumn{2}{|c|}{ Hook angles $\left({ }^{\circ}\right)$} & \multicolumn{2}{|c|}{ Hook height $(\mathrm{mm})$} \\
\hline & & & & $L 1$ & $L 2$ & $L 3$ & $L 4$ & $\alpha$ & $\beta$ & $H 1$ & $H 2$ \\
\hline 3D $65 / 60 \mathrm{BG}$ & 1150 & 60 & 0.90 & 2.12 & 2.95 & - & - & 45.7 & 47.5 & 1.85 & - \\
\hline 4D 65/60 BG & 1500 & 60 & 0.90 & 2.98 & 2.62 & 3.05 & - & 35.1 & 33.8 & 4.37 & 2.20 \\
\hline $5 \mathrm{D} 65 / 60 \mathrm{BG}$ & 2300 & 60 & 0.90 & 2.57 & 2.38 & 2.57 & 2.56 & 27.9 & 30.5 & 2.96 & 1.57 \\
\hline
\end{tabular}

provided by the manufacturer, are also summarized in Table 2.

\subsection{Sample preparation}

The pull-out tests on single steel fibre were performed using the cube of $(100 \times 100 \times 100 \mathrm{~mm})$ for NSC,
MSC and HSC, and cylinder of (100 mm diameter and $50 \mathrm{~mm}$ height) for UHPM. In each specimen, one steel fibre was placed carefully in a hole made through the bottom of moulds. The embedded length $\left(L_{\mathrm{E}}\right)$ was one half of the fibre length $(30 \mathrm{~mm})$. For compressive strength test three cubes of $(100 \times 100 \times 100 \mathrm{~mm})$ were prepared for each cementitious mixture. The 
mixtures were prepared using a laboratory Pan mixer for NSC, MSC and HSC, and Hobart mixer for UHPM. During specimen fabrication, the components were firstly dry mixed for approximately $1 \mathrm{~min}$ followed by the addition of water and superplasticizer (for HSC and UHPM) to the dry mixture. The mixture was then mixed for $11 \mathrm{~min}$. After casting and vibration, the specimens were covered with a thin polyethylene film and left for $24 \mathrm{~h}$ at room temperature. Then specimens were removed from their moulds and cured for a further 28 days in the conditioning chamber $\left(20 \pm 2{ }^{\circ} \mathrm{C}, 96 \pm 4 \% \mathrm{RH}\right)$. For both compressive and pull-out specimens, the test was carried out at an age of $30 \pm 2$ days and the average value of three specimens was adopted.

\subsection{Test setup}

The pull-out tests were performed using a specially designed grip system, as illustrated in Fig. 2, which was attached to an Instron 5584 universal testing machine. The grips were designed such that the forces applied to the fibre provided a true reflection of the real situation experienced by fibres bridging a crack. The body of the gripping system was machined in a lathe using mild steel and had a tapered end to allow the insertion of four M4 grub screws (Fig. 2). These were then tightened around the steel fibre to an equal torque for an even distribution of gripping pressure to minimise the deformation of the fibre ends and avoid breakage at the tip. Two linear variable differential transformer (LVDT) transducers were used to measure the distance travelled by the steel fibre relative to the concrete face during testing (i.e. the pull-out distance). They were held in place using aluminium sleeves on either side of the main grip body (Fig. 2). The LVDT's had ball bearings at the tips to allow for accurate readings on the face of the samples. The sample was secured to the Instron base using clamps with riser blocks and M16 studs. The specimen was positioned on a brass round disc to remove any discrepancies in the sample base and allow for distortion. In all pull-out tests, a displacement rate of $10 \mu \mathrm{m} / \mathrm{s}$ was adopted.

Fig. 2 Pull-out test setup

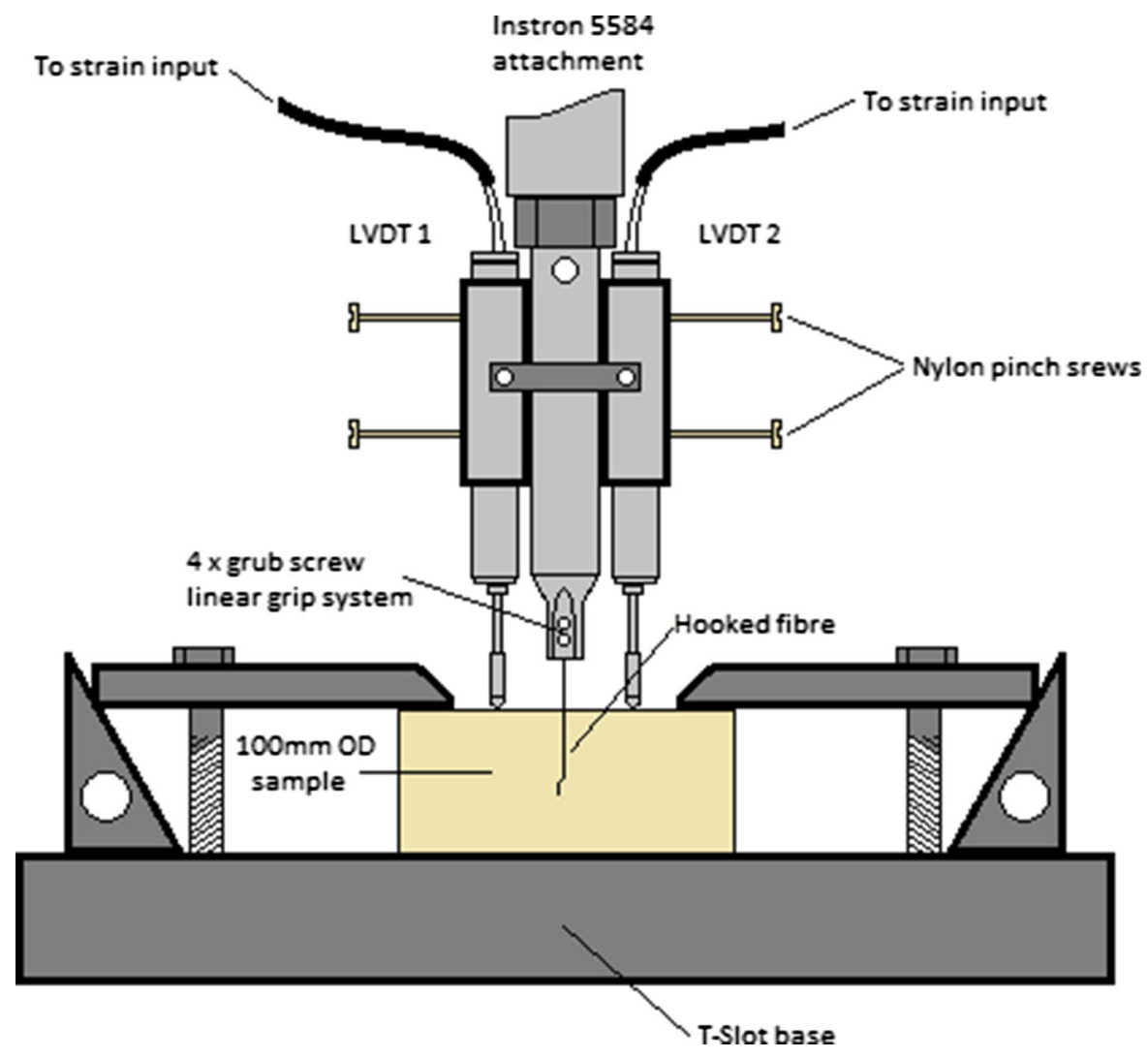




\section{Results and discussion}

\subsection{Effect of hook geometry on pull-out behaviour}

The effect of the end hook geometry on the pull-out behaviour was evaluated by comparing pull-out results from fibres of the same length, diameter, aspect ratio, embedment length, matrix strength with the only variable being the end hook geometry. The average pull-out-slip curves (three specimens) of all fibres embedded in different matrix strength are presented in Fig. 3 for comparison. Table 3, also summarizes the average maximum pull-out load $\left(P_{\max }\right)$ and total pullout work $\left(W_{\text {total }}\right)$ values as well as the corresponding coefficient of variation (C.o.V.\%).

It can be seen that the shape of the curves for $5 \mathrm{DH}$ fibres embedded in NSC and MSC matrixes behaves differently from the HSC and UHPM ones (Fig. 3). The initial incline of the pull-out curve up to peak load is similar for all matrixes, but post-peak behaviour both NSC and MSC curves exhibit a steeper load drop than the slopes of the fibres pulled from the HSC and UHPM. Further, the residual pull-out strength of 5DH fibres embedded in concrete matrixes (i.e. NSC, MSC, and HSC) is remarkably higher than that corresponding to the mortar matrix (UHPM). These differences can be attributed to the remaining irregularities at the fibre end due to incomplete the deformation and straightening of the hook. While the shape of pull-out curves of the $3 \mathrm{DH}$ and $4 \mathrm{DH}$ fibres does not vary significantly in the concrete matrixes. Both fibres in the post-peak region exhibit a sudden load drop at slip less than $5 \mathrm{~mm}$ when embedded in UHPM matrix. It can also be observed that overall the end hook geometry has a significant influence on the pull-out response. The high anchorage effect provided by the lengthy hook of 4DH and 5DH fibres significantly enhances the pull-out behaviour, generating higher pull-out load and pull-out work as compared to $3 \mathrm{DH}$ fibre. The anchorage strength also increases with increasing matrix compressive strength.

A scrutiny of results indicates that the maximum pull-out strength of 3DH-NSC combination is much lower, only slightly higher than $1 / 2$ those of $4 \mathrm{DH}$ - and 5DH-NSC which are very similar (Fig. 3a). A comparison of the pull-out behaviour of these fibres in the NSC (Fig. 3a) with that in the MSC (Fig. 3b) clearly showed that the pull-out strength of 5DH fibre is considerably increased probably due to the enhancement of the matrix compressive strength. With the NSC matrix, the maximum pull-out load of $5 \mathrm{DH}$ fibre is about 73 and $11 \%$ that of the $3 \mathrm{DH}$ and $4 \mathrm{DH}$ fibres respectively and the corresponding difference in total pull-out work is 92 and 53\% respectively. Similarly, for the 5DH fibre in MSC, the maximum pull-out load are 117, 55\%, and pull-out work 92 and $93 \%$ higher than that for the $3 \mathrm{DH}$ and $4 \mathrm{DH}$ fibres respectively. This significant difference in pull-out work can be attributed to variation in slip capacity as a result of different pull-out mechanisms. As aforementioned, improving the matrix compressive strength significantly increases both the maximum pull-out load and pull-out work of all fibres (Fig. 3c, d). Again, the maximum pull-out load of 5DH fibres embedded in both HSC and UHPM is about 101 and $63 \%$ that of the $3 \mathrm{DH}$ fibre, while for the $4 \mathrm{DH}$ fibre the corresponding values are only 31 and $27 \%$ respectively.

The C.o.V. of both the average $P_{\max }$ and $W_{\text {total }}$ indicates the consistency of the test results with the C.o.V. values below or around 10\% (Table 3), except, the deviations in case of 4DH and 5DH fibres embedded in the NSC and MSC. As some of 4DH and 5DH fibres were not fully deformed and straightened during pull-out tests.

\subsection{Effect of matrix strength on pull-out behaviour}

Four different matrixes (NSC, MSC, HSC and UHPM) with compressive strengths ranging from 33 to $148 \mathrm{MPa}$ are used (Table 2) to investigate the influence of matrix compressive strength on the pull-out behaviour of fibres with various hook geometry. It can be seen from the Fig. 4 that the pull-out response of all fibres has varied dramatically with matrix strength. For all fibres, the pull-out response is strongly dependent on the matrix strength. The variability of the pull-out response is found to be higher in the case of 5DH fibre than 3DH and 4DH fibres. Therefore, the variability of the pull-out response can be attributed to the variations in the level of deformation and straightening of the hook. The maximum pull-out load and pull-out work significantly increase as the matrix strength increases for all fibres (Fig. 4). The percent increase in the maximum pull-out load of 3DH fibre in ascending order is 27,78 and $134 \%$ as the matrix compressive strength increased from NSC $\left(f_{\mathrm{c}}=33 \mathrm{MPa}\right)$ to $\mathrm{MSC} \quad\left(f_{\mathrm{c}}=52 \mathrm{MPa}\right)$, HSC $\left(f_{\mathrm{c}}=71 \mathrm{MPa}\right)$ and UHPM $\left(f_{\mathrm{c}}=148 \mathrm{MPa}\right)$, while 
Fig. 3 Comparative average pull-out behaviour of 3DH, 4DH and 5DH fibres: a NSC, b MSC, c HSC and d UHPM matrixes
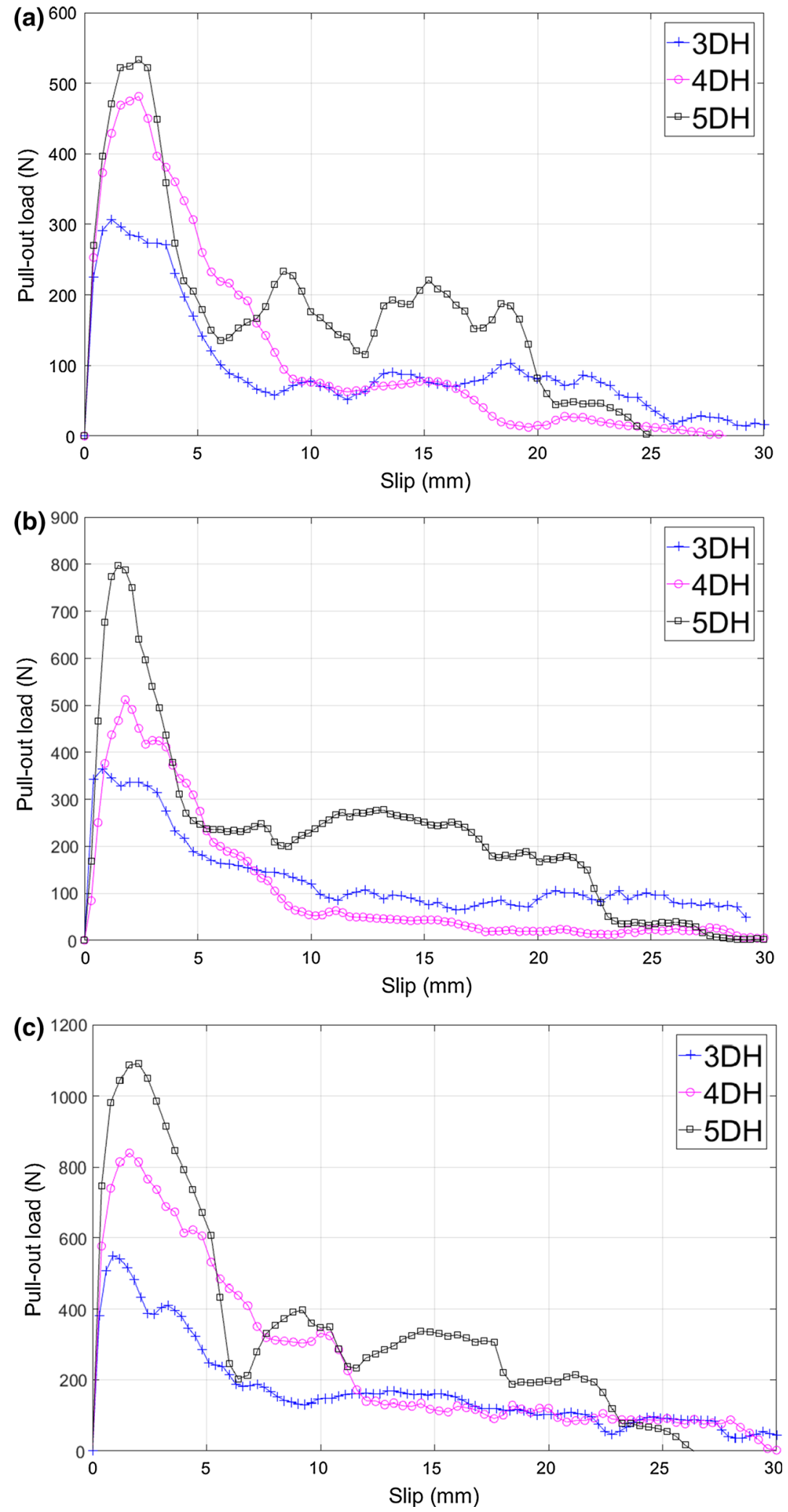
Fig. 3 continued

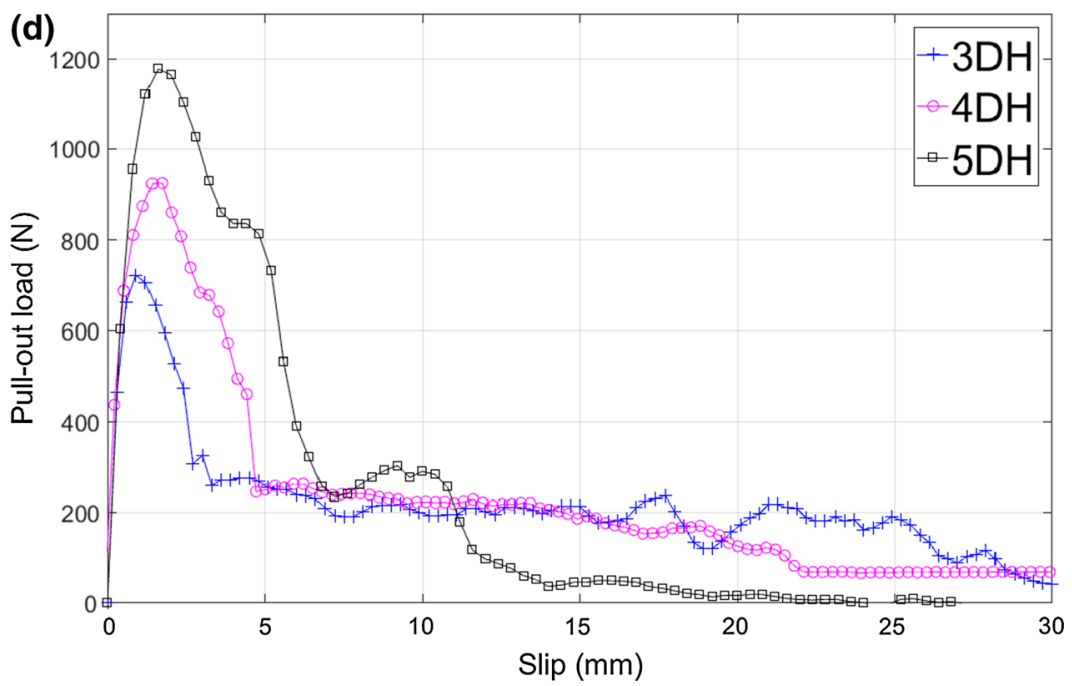

Table 3 Average and scattering of the pull-out results

\begin{tabular}{llcclcl}
\hline Fibre type & Matrix & $P_{\max }(\mathrm{N})$ & C.o.V. $(\%)$ & $W_{\text {total }}(\mathrm{N} \mathrm{mm})$ & C.o.V. $(\%)$ & Failure mode \\
\hline 3 DH & NSC & 309 & 10.1 & 2437 & 8.8 & Pull-out \\
& MSC & 391 & 9.2 & 3445 & 6.4 & Pull-out \\
& HSC & 549 & 7.5 & 4446 & 5.1 & Pull-out \\
& UHPM & 723 & 4.3 & 5948 & 4.8 & Fibre rupture \\
4 & NSC & 484 & 14.4 & 3065 & 20.5 & Pull-out \\
& MSC & 595 & 9.5 & 3445 & 16.4 & Pull-out \\
& HSC & 840 & 6.4 & 7509 & 12.6 & Pull-out \\
$5 \mathrm{~F} H$ & UHPM & 933 & 1.5 & 6592 & 9.7 & Fibre rupture \\
& NSC & 537 & 23.7 & 4682 & 26.6 & Pull-out \\
& MSC & 799 & 18.6 & 6625 & 17.3 & Pull-out \\
& HSC & 1101 & 9.9 & 9721 & 10.7 & Pull-out \\
& UHPM & 1181 & 4.7 & 7568 & 7.8 & Pull-out \\
\hline
\end{tabular}

the corresponding increase in the total pull-out work is 41,82 , and $144 \%$ respectively. Both $4 \mathrm{DH}$ and $5 \mathrm{DH}$ fibres behaved in the HSC and UHPM better than in NSC and MSC. In comparison with the NSC matrix, the percent increase of HSC matrix is about 74 and $105 \%$, while the percent increase in UHPM is 92 and $119 \%$ respectively.

Figure 5 illustrates the influence of matrix strength on the pull-out work of 3DH, $4 \mathrm{DH}$ and $5 \mathrm{DH}$ fibres. The values of pull-out work are determined by calculating the area under the pull-out load-slip curves. It is evident that the pull-out work increases significantly with increasing matrix compressive strength for all fibres. With the increase in matrix compressive strength from 33 to $52 \mathrm{MPa}$, an increase of about 41,13 and $42 \%$ pull-out work was observed for $3 \mathrm{DH}, 4 \mathrm{DH}$ and $5 \mathrm{DH}$ fibres respectively. With the further increase in compressive strength from 33 to $71 \mathrm{MPa}$, an increase of approximately 82, 145 and $108 \%$ pull-out work was observed for $3 \mathrm{DH}, 4 \mathrm{DH}$ and $5 \mathrm{DH}$ fibres respectively. Interestingly, the pull-out work of 5DH fibre is greatly higher than the $3 \mathrm{DH}$ and $4 \mathrm{DH}$ ones in all matrixes. However, the pull-out work of both the 4DH and 5DH fibres pulled from the HSC is 14 and $28 \%$ higher than the corresponding value in the UHPM. These differences can be attributed to the remaining irregularities at the fibre end that, together with the presence of coarse aggregates in concrete, increase the residual pull-out strength. Similar behaviour is also reported by other researchers [23, 24]. 
Fig. 4 Effect of matrix strength on average pull-out load-slip curves: a 3DH, b $4 \mathrm{DH}$ and c 5DH fibres
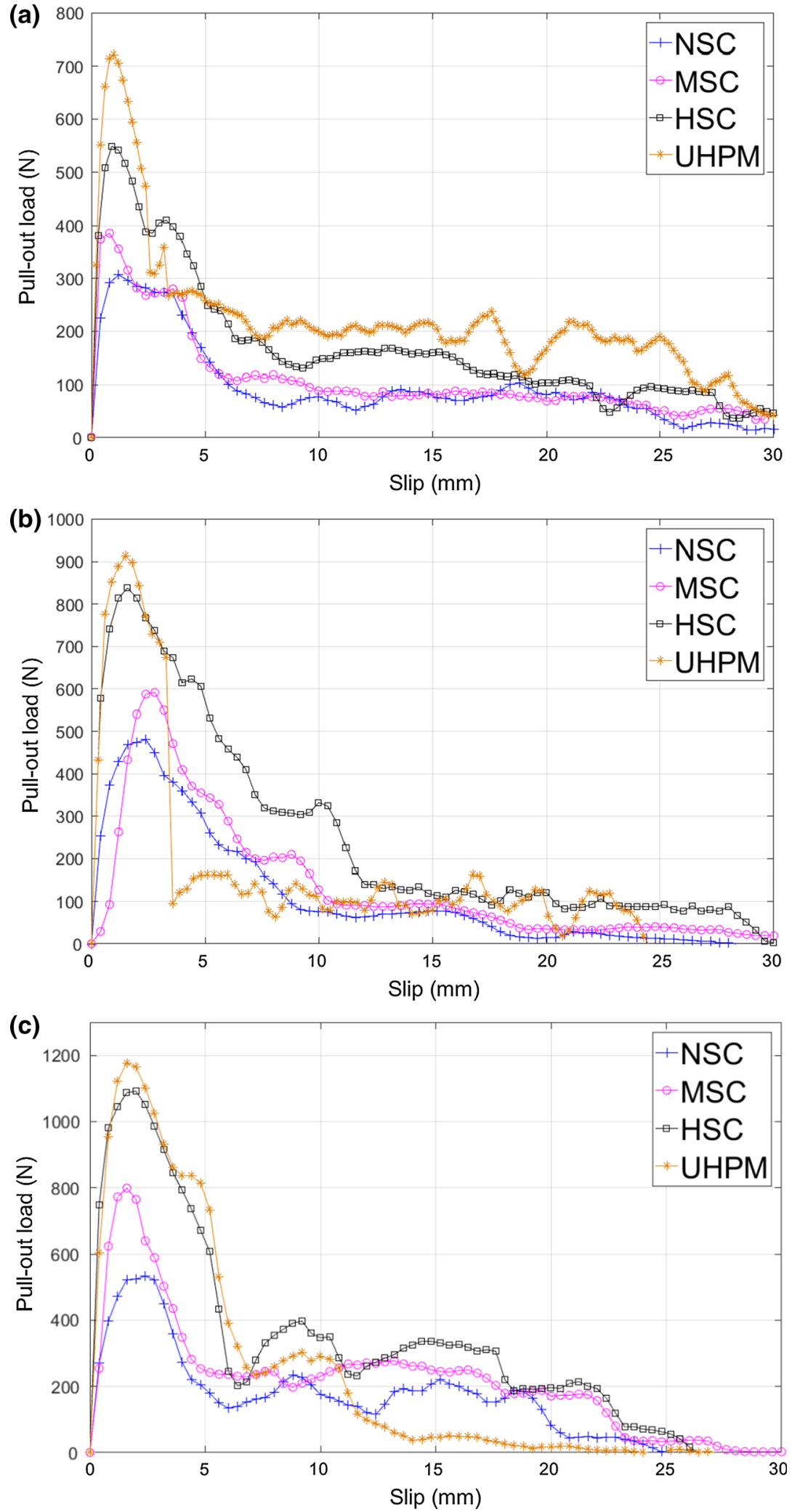


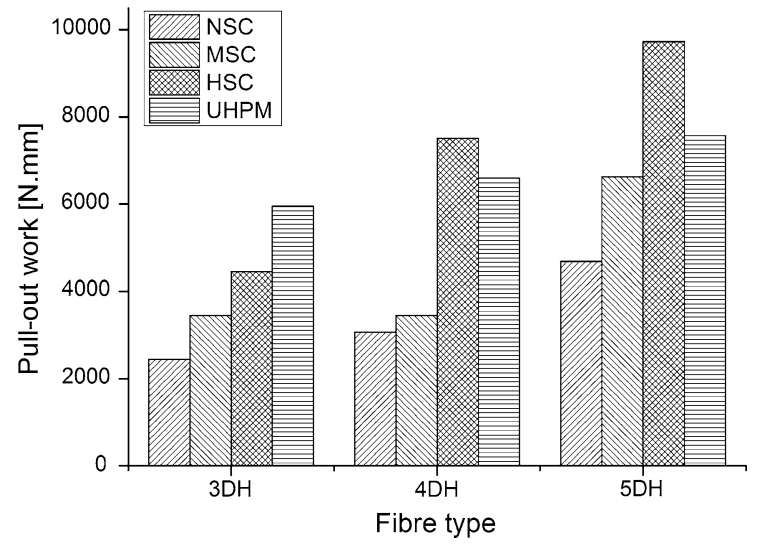

Fig. 5 Total pull-out work of various combinations

\subsection{Deformation of the hook}

To further understand the influence of the hook geometry and matrix compressive strength on the pull-out response, deformation and straightening process of the 3DH, 4DH and 5DH fibres from different matrixes were investigated. It is evident that the $3 \mathrm{DH}$ and 4DH fibres embedded in NSC and MSC are completely pulled out without occurrence of fully deformation and straightening of the hooks (Fig. 6). However, the influence of matrix compressive strength on deformation and straightening of the hooks becomes much more pronounced when the fibres were pulled out from the HSC and UHPM matrixes. While the full deformation and straightening of the hooks occurs, the rupture of both fibres in the latter matrix at the hook portion has been observed. These differences may be due to the enhanced matrix properties which lead to better bonding strength between fibre and matrix. This leads to the conclusion that the level of deformation and straightening of the hook are significantly different depending on which matrix they are pulled from.

For the 5DH fibres, the following interesting points could be drawn: (1) the complete deformation of fibre hook embedded in the NSC matrix did not occur rather only low level of deformation and straightening of the hook have been observed (Fig. 6), (2) this partial deformation dramatically increases with increasing the matrix compressive strength, (3) the full deformation and straightening of 5DH fibre hook only take place when the fibres embedded in UHPM, (4) in all four matrixes, the $5 \mathrm{DH}$ fibre is completely pulled out from the specimen without an occurrence of the fibre rupture, (5) as a result of unique hook's geometry and high tensile strength of 5DH fibre, matrix with high compressive strength is needed to ensure the full utilization of hook anchorage which makes this type of fibre attractive for use in ultra-high performance cementitious composites, and (6) this leads to the conclusion that the 5DH fibre used in this study may only be fully exploited as the reinforcement in UHPM.

\subsection{Fibre rupture}

A scrutiny of the morphology of deformation shows that the 3DH and 4DH fibres embedded in NSC, MSC and HSC are completely pulled out from the specimens without the occurrence of fibre rupture (Fig. 6). However, when both fibres pulled out from the UHPM matrix, the fibre rupture takes place during the early stages of the pull-out process. This is in agreement with the pull-out load (Fig. 4a), which of 3DH fibre dropped sharply at slip of approximately $3.5-4.5 \mathrm{~mm}$ and this means that the fibre rupture at hook portion.

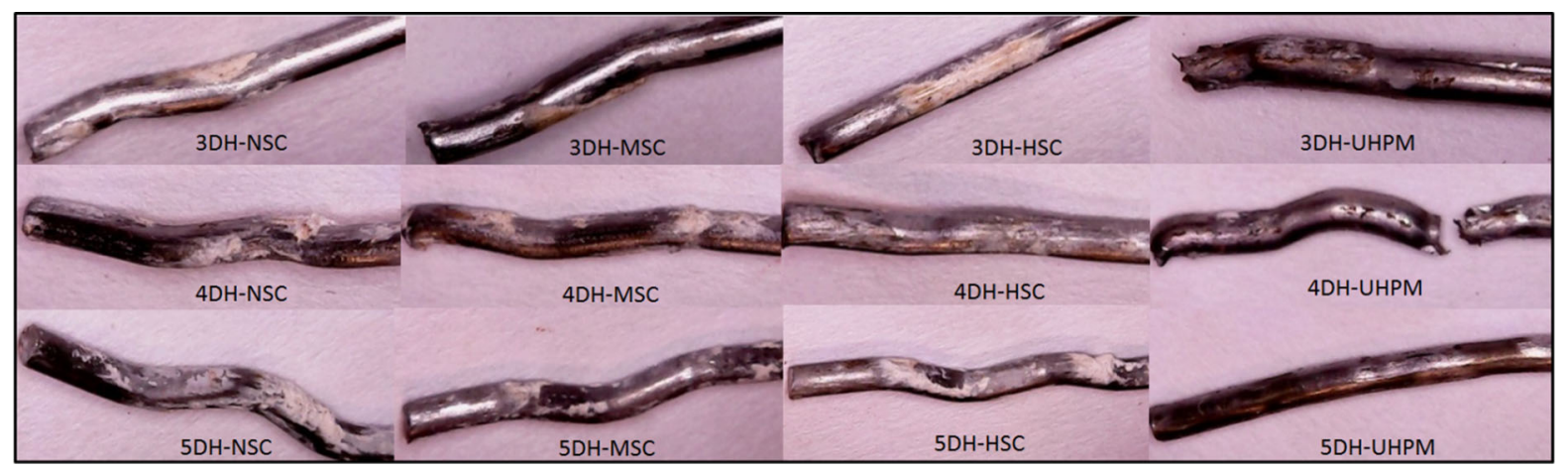

Fig. 6 Deformation and straightening of hook after pull-out test 
This could be due to an attainment of the ultimate tensile capacity of the steel at the hook part. Bearing in mind that the hook length of $3 \mathrm{DH}$ fibres is approximately $5 \mathrm{~mm}$, this indicates that the fibre rupture was likely to take place at last portion of the hook (within L2 region, Table 2) as demonstrated in (Fig. 6). Like the $3 \mathrm{DH}$ fibre, the pull-out behaviour of 4DH fibre is characterized by an ascending increase of pull-out load up to maximum value, generally followed by a sudden drop of load, indicating fibre partially rupture. By contrast, the rupture of 4DH fibre occurs roughly at 2-4.5 mm (Fig. 4b) which corresponding approximately to the L1 and L2 (Table 2; Fig. 6) region. The fact that this fibre is bent several times at each curvature results in a significantly worn down of the fibre at hook part. As a consequence, the tensile strength of steel fibre at the hook portion decreases due to excessive deformation and hence the fibre becomes more susceptible to rupture. Although the fibre rupture took places at early stages of pull-out, Fig. 4a, b show the fibre continues transfer the stress till fibre completely pulled out.

On the other hand, due to the high mechanical anchorage of the 4DH fibre compared with its tensile strength $\left(f_{\mathrm{y}}=1500 \mathrm{MPa}\right)$, the rupture of fibre is more likely to occur in very high matrix strength. That is, the fibre rupture tends to occur when the fibre with high mechanical anchorage and low tensile strength is combined with high matrix strength [23]. This indicates that the mechanical anchorage contribution of $4 \mathrm{DH}$ fibre can be completely reflected if fibre rupture is prevented. Therefore, the tensile strength of $4 \mathrm{DH}$ fibre has to increase in parallel with the strength of its anchorage. Only in this way can the fibre resist the forces acting upon it. On the basis of these considerations, it is believed that increasing the tensile strength of the 4DH fibre would effectively prevent fibre rupture and capitalize the end hook anchorage strength to the maximum degree.

\section{Conclusions}

The pull-out behaviour of various hooked-end steel fibres in combination with various cementitious matrixes has been thoroughly investigated. Some specific conclusions can be drawn as follows:
(1) The pull-out behaviour of a hooked end fibre was significantly influenced by the hook geometry and compressive strength of the matrix. The combined effect and balance of the constituents' contribution determined the maximum failure load, failure region and many other failure parameters. The maximum pull-out load and total pull-out work of the 5DH fibre were much higher than that of the $3 \mathrm{DH}$ and $4 \mathrm{DH}$ fibres in all matrixes.

(2) All fibres embedded in NSC and MSC matrixes were completely pulled out without the occurrence of full deformation and straightening of the hook. The hook of the 3DH and 4DH fibres fully deformed and straightened when embedded in HSC, while the 5DH fibre only occurred in UHPM. This leads to the fact that the 5DH fibre can only be fully effective when used in UHPM.

(3) The fibre rupture tended to occur when the fibre with high mechanical anchorage but low tensile strength (e.g. 3DH and 4DH) was combined with high matrix strength (e.g. UHPM). Although the load sharply dropped after fibre rupture took place, remaining part of fibre continued to transfer part pull-out load.

(4) For 4DH fibre, the mechanical anchorage contribution provided by the hook could be greatly increased by increasing the tensile strength of the fibre. To fully utilize the high mechanical anchorage, 5DH fibres should be used for reinforcing high or ultra-high performance matrixes in practice.

Funding The first author gratefully acknowledges the scholarship of the Ministry of Higher Education and Scientific Research of Iraqi Government for this Ph.D. project.

\section{Compliance with ethical standards}

Conflict of interest The authors declare that they have no conflict of interest.

Open Access This article is distributed under the terms of the Creative Commons Attribution 4.0 International License (http:// creativecommons.org/licenses/by/4.0/), which permits unrestricted use, distribution, and reproduction in any medium, provided you give appropriate credit to the original author(s) and the source, provide a link to the Creative Commons license, and indicate if changes were made. 


\section{References}

1. Foster SJ (2009) The application of steel-fibres as concrete reinforcement in Australia: from material to structure. Mater Struct 42:1209-1220

2. Cavalaro SHP, López R, Torrents JM, Aguado A (2015) Improved assessment of fibre content and orientation with inductive method in SFRC. Mater Struct 48:1859-1873

3. Zheng W, Luo B, Wang Y (2015) Stress-strain relationship of steel-fibre reinforced reactive powder concrete at elevated temperatures. Mater Struct 48:2299-2314

4. Duque LFM, Graybeal B (2017) Fiber orientation distribution and tensile mechanical response in UHPFRC. Mater Struct 50:55

5. Abdallah S, Fan M, Zhou X, Geyt S (2016) Anchorage Effects of Various Steel Fibre Architectures for Concrete Reinforcement. Int J Concr Struct Mater 10:325-335

6. Minelli F, Conforti A, Cuenca E, Plizzari G (2014) Are steel fibres able to mitigate or eliminate size effect in shear? Mater Struct 47:459-473

7. Ng TS, Foster SJ, Htet ML, Htut TNS (2014) Mixed mode fracture behaviour of steel fibre reinforced concrete. Mater Struct 47:67-76

8. Boulekbache B, Hamrat M, Chemrouk M, Amziane S (2015) Failure mechanism of fibre reinforced concrete under splitting test using digital image correlation. Mater Struct 48:2713-2726

9. Zhao G, di Prisco M, Vandewalle L (2015) Experimental investigation on uniaxial tensile creep behavior of cracked steel fiber reinforced concrete. Mater Struct 48:3173-3185

10. Van Zijl GPAG, Wittmann FH (eds) (2011) Durability of strain-hardening fibre-reinforced cement-based composites (SHCC). State-of-the-art report, Rilem TC 208 HFC, SC 2, Springer Publishers, ISBN-13: 978-94-007-0337-7

11. Wang D, Shi C, Wu Z, Xiao J, Huang Z, Fang Z (2015) A review on ultra high performance concrete: part II. Hydration, microstructure and properties. Constr Build Mater 96:368-377

12. Jewell RB, Mahboub KC, Robl TL, Bathke AC (2015) Interfacial bond between reinforcing fibers and calcium sulfoaluminate cements: fiber pullout characteristics. ACI Mater J 112:39

13. Daviau-Desnoyers D, Charron J, Massicotte B, Rossi P, Tailhan J (2016) Characterization of macrocrack propagation under sustained loading in steel fibre reinforced concrete. Mater Struct 49:969-982

14. Abdallah S, Fan M, Rees DWA (2016) Analysis and modelling of mechanical anchorage of 4D/5D hooked end steel fibres. Mater Des 112:539-552

15. Abbas YM, Khan MI (2016) Fiber-Matrix Interactions in Fiber-Reinforced Concrete: a Review. Arab J Sci Eng 41:1183-1198

16. Laranjeira F, Molins C, Aguado A (2010) Predicting the pullout response of inclined hooked steel fibers. Cem Concr Res 40:1471-1487

17. Georgiadi-Stefanidi K, Mistakidis E, Pantousa D, Zygomalas M (2010) Numerical modelling of the pull-out of hooked steel fibres from high-strength cementitious matrix, supplemented by experimental results. Constr Build Mater 24:2489-2506

18. Zìle E, Zīle O (2013) Effect of the fiber geometry on the pullout response of mechanically deformed steel fibers. Cem Concr Res 44:18-24

19. Tuyan M, Yazıc1 H (2012) Pull-out behavior of single steel fiber from SIFCON matrix. Constr Build Mater 35:571-577

20. Laranjeira F, Aguado A, Molins C (2010) Predicting the pullout response of inclined straight steel fibers. Mater Struct 43:875-895

21. Robins P, Austin S, Jones P (2002) Pull-out behaviour of hooked steel fibres. Mater Struct 35:434-442

22. Abu-Lebdeh T, Hamoush S, Heard W, Zornig B (2011) Effect of matrix strength on pullout behavior of steel fiber reinforced very-high strength concrete composites. Constr Build Mater 25:39-46

23. Beglarigale A, Yazıc1 H (2015) Pull-out behavior of steel fiber embedded in flowable RPC and ordinary mortar. Constr Build Mater 75:255-265

24. Isla F, Ruano G, Luccioni B (2015) Analysis of steel fibers pull-out. Experimental study. Constr Build Mater 100:183-193 